\title{
Measuring Drained Residual Strengths in the Bromhead Ring Shear
}

\author{
Christopher L. Meehan ${ }^{1}$; Thomas L. Brandon ${ }^{2}$; J. Michael Duncan ${ }^{3}$
}

\begin{abstract}
A series of Bromhead ring shear tests were conducted to measure the drained residual strength of Rancho Solano Fat Clay. Tests conducted using different test procedures demonstrate the significant effect that wall friction can have in the Bromhead ring shear device. This problem was addressed by beveling the top loading platen, which led to measurements of drained residual strength that were 21-23\% lower than those measured with the unmodified platen. Using the modified platen, similar test results can be achieved independent of the details of the test procedure that is followed, giving greater confidence in the measured residual shear strength.
\end{abstract}

\section{DOI: $10.1520 /$ GTJ101017}

Keywords: Ring shear tests; Clays; Residual strength; Slickensides; Laboratory test; Shear tests.

Copyright: This paper is part of the Geotechnical Testing Journal, Vol.30, No.6, November 2007, ISSN $1945-7545$. The copyright for this work is held by ASTM International. The original publication of this work can be obtained by following the DOI link above.

Reference: Meehan, C.L., Brandon, T.L., and Duncan, J. M. (2007). "Measuring Drained Residual Strengths in the Bromhead Ring Shear." Geotechnical Testing Journal, ASTM, 30(6), 466-473. (doi:10.1520/GTJ101017)

Note: The manuscript for this paper was submitted for review and possible publication on January 18, 2007; approved for publication on April 20, 2007; and published online in June of 2007.

\section{Introduction}

For existing landslides in overconsolidated clay and clay shale slopes, stability of the slope is controlled by the shear resistance that can be mobilized along slickensided shear surfaces (Skempton 1985). Slickensided shear surfaces are formed in clay soils as a result of shear on distinct planes of slip, which aligns the plate-like clay particles parallel to the plane of slip (Duncan and Wright 2005). The drained shear strength along slickensided surfaces is called the residual strength, and is the lowest strength that can be measured for a clay soil (Skempton 1964).

For stability analyses of active landslides, it is important to characterize the residual strength of the soil accurately. Reversal direct shear tests and torsional ring shear tests are the two approaches that are most commonly used to measure the residual strength of the soil (USACE 1986; ASTM D 6467). A large number of correlations have also been proposed between the residual friction angle and fundamental clay properties, such as clay fraction or Atter-

\footnotetext{
${ }^{1}$ Assistant Professor, University of Delaware, Dept. of Civil and Environmental Engineering, 301 DuPont Hall, Newark, DE 19716, U.S.A. E-mail: cmeehan@udel.edu (corresponding author)

${ }^{2}$ Associate Professor, Virginia Tech, Dept. of Civil and Environmental Engineering, 200 Patton Hall, Blacksburg, VA 24061, U.S.A. E-mail: tbrandon@vt.edu

${ }^{3}$ Univ. Distinguished Professor, Virginia Tech, Dept. of Civil and Environmental Engineering, 200 Patton Hall, Blacksburg, VA 24061, U.S.A. E-mail: jmd@vt.edu
}

berg limits (e.g., Lupini et al. 1981; Stark and Eid 1994; Tiwari and Marui 2005). The reliability of these residual strength correlations is heavily dependent on the accuracy of the device that was used to measure the drained residual strength.

Significant differences are sometimes observed between residual strengths measured in the reversal direct shear device and the torsional ring shear device (Bishop et al. 1971). Because of these differences, and because the ring shear device can apply unlimited shear displacement without reversal in the direction of shear, the torsional ring shear test has become the preferred test for measuring the residual shear strength of soils (Duncan and Wright 2005).

In the United States, the Bromhead ring shear device (Bromhead 1979) is widely used for measuring the drained residual strength of clay soils. In the Bromhead ring shear, a thin annular soil specimen is subjected to torsional, displacement-controlled shearing under a constant normal stress. As shown in Fig. 1, failure occurs by rupture of the soil specimen along its upper surface, where a thin layer of clay particles that adhere to the roughened upper platen are displaced relative to clay particles below. Continued shearing results in clay particle orientation along the failure plane, and the development of slickensides along which the residual strength is measured.

This paper presents the results from a series of Bromhead ring shear tests that were conducted to measure the 


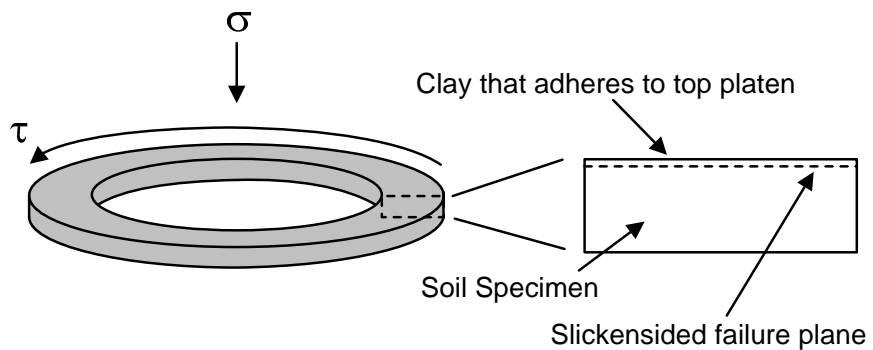

Fig. 1: Formation of a slickensided failure plane in a Bromhead ring shear specimen.

drained residual strength along slickensided discontinuities in Rancho Solano Fat Clay. These tests were conducted as part of a larger research project that is examining the static and dynamic shear behavior of slickensided surfaces using ring shear, direct shear, triaxial, and centrifuge model tests (Meehan 2006). A series of tests conducted using varying test procedures illustrate the significant effect that wall friction has in the Bromhead ring shear device. A simple modification to the Bromhead ring shear can be used to address the effect of wall friction, allowing more accurate residual friction angles to be measured using this device.

\section{Soil Properties}

The ring shear tests described in this paper were performed on "Rancho Solano Fat Clay" from the Rancho Solano residential development in Fairfield, California. This soil was batch-mixed at water contents ranging from 1.0 to 1.2 times its liquid limit to ensure uniformity. The clay slurry was then passed through a \#40 sieve to remove larger soil particles that could interfere with operation of the Bromhead ring shear device.

Index tests on the resulting slurry yielded the following properties: Liquid Limit (LL) of 61, Plastic Limit (PL) of 25 , Plasticity Index (PI) of 36, fines content (percent by dry weight passing the \#200 sieve) of $93 \%$, clay size fraction (smaller than 2 micron) of $53 \%$, and specific gravity of solids $=2.65$. The USCS Classification for this soil is "fat clay $(\mathrm{CH})$. ."

\section{The Drained Residual Shear Strength}

The ring shear tests described in this paper were performed at Virginia Tech using two Bromhead ring shear devices built by Wykeham Farrance Engineering Ltd. Fig. 2 is a photograph of a Bromhead ring shear apparatus of the type used in this study. The test specimens used in this apparatus had inside diameters of $70.0 \mathrm{~mm}$, outside diameters of $100.0 \mathrm{~mm}$, and initial thicknesses (prior to consolidation) of $5.0 \mathrm{~mm}$.

A series of drained ring shear tests was first conducted on the test soil using the test procedure that is described in the Standard Test Method for Torsional Ring Shear Test to Determine Drained Residual Shear Strength of Cohesive Soils (ASTM D 6467-99). The clay was processed as described above before testing.

To begin each test, the processed clay was spread in the

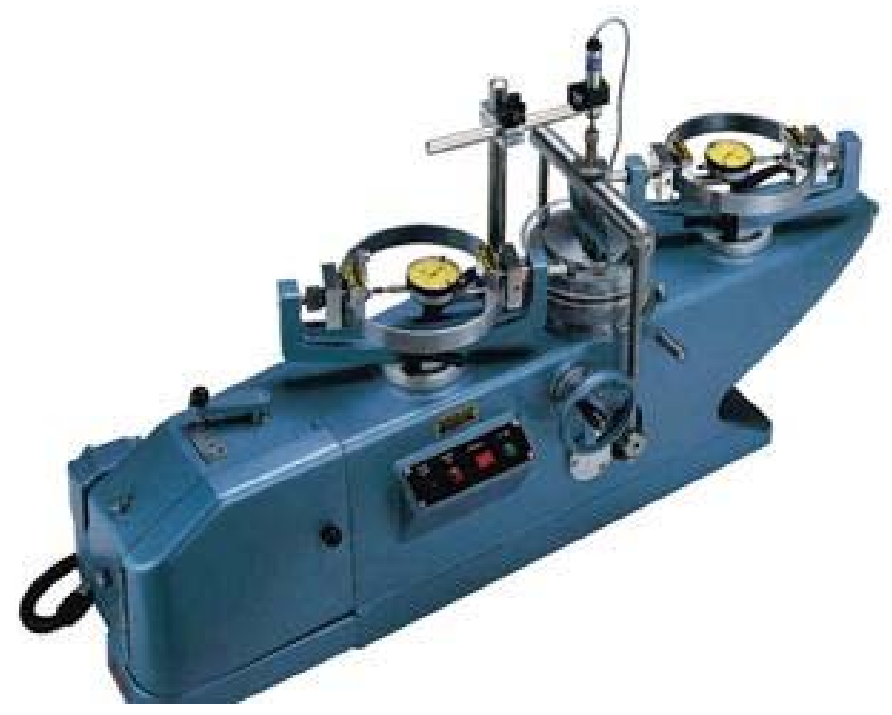

Fig. 2: Bromhead ring shear apparatus.

Bromhead ring shear specimen container using a spatula. The specimen container was then placed in the device, and the specimen was consolidated using a series of load steps to a final consolidation stress of $200 \mathrm{kPa}$. During consolidation, the normal force was applied by a dead-weight leverarm system, and vertical displacements were recorded to ensure that consolidation for a given load step was complete before the next load was applied.

Once consolidation under the $200 \mathrm{kPa}$ pressure was complete, the test specimen was unloaded to a normal stress of $52 \mathrm{kPa}$, and allowed to come to equilibrium. Once equilibrium was achieved, the specimen was presheared for one complete revolution (a shear displacement of about 270 $\mathrm{mm}$ ) at a rate of $14.7 \mathrm{~mm} / \mathrm{min}$ in order to create a slickensided failure plane within the specimen. This allowed for more rapid measurement of the drained residual shear strength, because a slickensided failure surface was produced in the specimen before slow shearing was begun.

Once the specimen had again reached equilibrium after preshearing, slow shearing was begun. In order to minimize possible shear-induced pore water pressures, slowshear displacement rates were selected using the following equation (from ASTM D 6467-99):

$$
\text { Disp. Rate }=\frac{\text { Disp. at Failure }}{\text { Time to Failure }}=\frac{5 \mathrm{~mm}}{50 \times t_{50}}
$$

In the above equation, $t_{50}$ is the time required for the specimen to achieve $50 \%$ consolidation under the specified normal stress. Table 1 lists the calculated displacement rates for the first series of ring shear tests performed on Rancho Solano Fat Clay. Based on the data given in Table 1, slow shearing of all specimens was performed at a displacement rate of $0.018 \mathrm{~mm} / \mathrm{min}$. This is a conservative lower bound displacement rate at which shear-induced pore pressures were negligible. This displacement rate is also the lowest displacement rate that can be applied by the Bromhead ring shear devices in the Virginia Tech laboratory.

Each specimen was first sheared at a normal stress of 


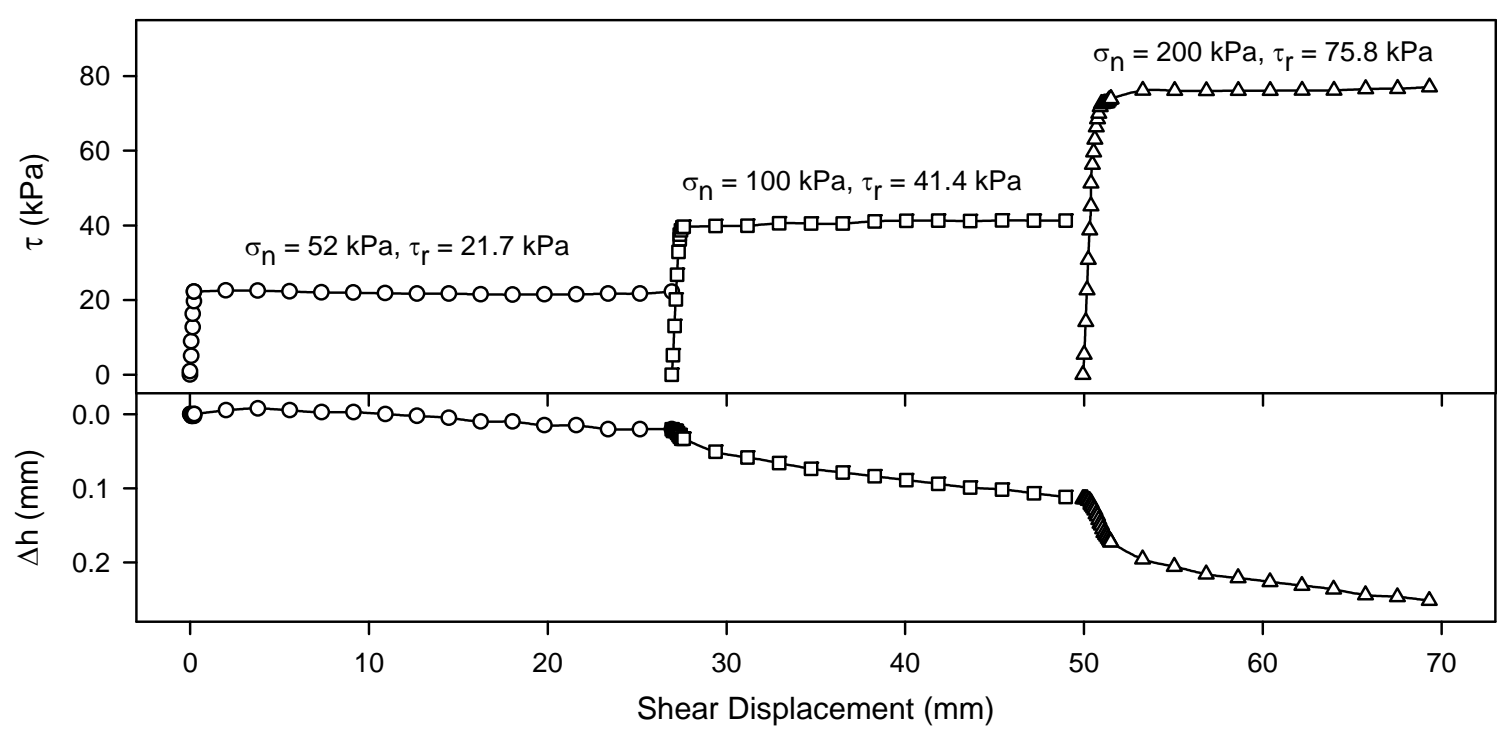

Fig. 3: Typical test results from a "presheared multistage" ring shear test.

Table 1: Calculated Displacement Rates for "Presheared Multistage" Ring Shear Tests

\begin{tabular}{lcc}
\hline & $\begin{array}{c}\text { Displacement Rate } \\
\text { Calculated Using } \\
\text { Casagrande } t_{50} \\
(\mathrm{~mm} / \mathrm{min})\end{array}$ & $\begin{array}{c}\text { Displacement Rate } \\
\text { Calculated Using } \\
\text { Taylor } t_{50} \\
(\mathrm{~mm} / \mathrm{min})\end{array}$ \\
\hline R1-052003-1, R1-052003-2, and R1-052003-3 & 0.061 & 0.061 \\
R1-060303-1, R1-060303-2, and R1-060303-3 & 0.069 & 0.124 \\
R1-061003-1, R1-061003-2, and R1-061003-3 & 0.051 & 0.084 \\
R1-061903-1, R1-061903-2, and R1-061903-3 & 0.030 & 0.041 \\
\hline
\end{tabular}

$52 \mathrm{kPa}$, until the measured shear resistance reached a constant value. Shearing was then stopped, and the normal stress on the specimen was increased to $100 \mathrm{kPa}$. After the specimen had come to equilibrium under the $100 \mathrm{kPa}$ pressure, the specimen was sheared again. Once the shear resistance had reached a constant value for the second shearing stage at $100 \mathrm{kPa}$ normal stress, the normal stress was increased to $200 \mathrm{kPa}$, for a third shearing stage. This "multistage" method reduced testing time considerably, because it was only necessary to prepare and consolidate one specimen for every three measurements of residual strength that were made.

Four "presheared multistage" ring shear tests were performed on Rancho Solano Fat Clay specimens. The test approach described above was used for each test, and residual strengths were measured at normal stresses of 52, 100, and $200 \mathrm{kPa}$ for each specimen. Typical test results are shown in Fig. 3. As expected, a constant value of residual shear stress was reached at small displacements for each shearing stage, because a slickensided surface had already been created by preshearing. Specimen height change measurements were heavily influenced by extrusion of the clay at the boundaries of the specimen, and consequently could not be used as an indicator of specimen void ratio change. As indicated by the change in height versus displacement plot shown in Fig. 3, more extrusion occurred at higher normal stresses.

Twelve measurements of residual shear stress were made during the four ring shear tests that were conducted following ASTM D 6467. Results of statistical analyses performed on the test data are given in Table 2. A plot of average residual shear stress versus normal stress along with the failure envelope is given in Fig. 4. This envelope was created by drawing a smoothed line from the origin through the average residual shear stress values.

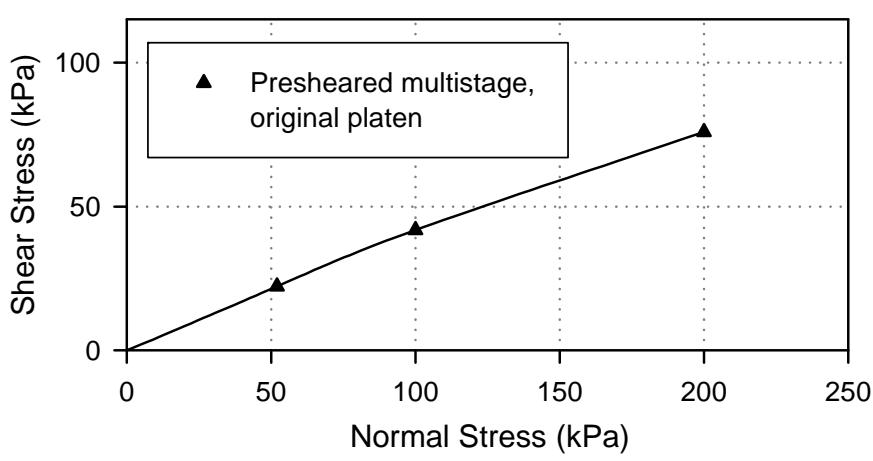

Fig. 4: Residual shear stresses measured in "presheared multistage" ring shear tests. 
Table 2: Residual Shear Stresses Measured in "Presheared Multistage" Ring Shear Tests

\begin{tabular}{lccccc}
\hline $\begin{array}{l}\text { Normal } \\
\text { Stress } \\
(\mathrm{kPa})\end{array}$ & $\begin{array}{c}\text { Number } \\
\text { of Tests } \\
\text { Performed }\end{array}$ & $\begin{array}{c}\text { Average } \\
\text { Residual } \\
\text { Shear Stress } \\
(\mathrm{kPa})\end{array}$ & $\begin{array}{c}\text { Standard Deviation of } \\
\text { Measured Residual } \\
\text { Shear Stress } \\
(\mathrm{kPa})\end{array}$ & $\begin{array}{c}\text { Minimum } \\
\text { Measured Residual } \\
\text { Shear Stress } \\
(\mathrm{kPa})\end{array}$ & $\begin{array}{c}\text { Measured Residual } \\
\text { Shear Stress } \\
(\mathrm{kPa})\end{array}$ \\
\hline 52 & 4 & 22.2 & 1.6 & 20.3 & 24.1 \\
100 & 4 & 41.9 & 1.2 & 40.7 & 43.4 \\
200 & 4 & 75.9 & 0.9 & 75.2 & 77.2 \\
\hline
\end{tabular}

The assumption that the residual strength envelope passes through the origin was chosen for simplicity, based on Skempton's (1964) observation that the residual cohesion intercept for overconsolidated clays is "very small, and probably not significantly different from zero." There has been some discussion on the accuracy of this assumption in recent literature, as cohesion values as large as $9.2 \mathrm{kPa}$ have been observed for "best fit" residual strength envelopes for some soils (Tiwari et al. 2005). Because the residual strength failure envelope is significantly curved for Rancho Solano Fat Clay, the "best fit" approach cannot be used, and it is necessary to assume a value for the residual cohesion intercept. The conclusions drawn in this paper are unaffected by this assumption. Further discussion of this phenomenon is outside the scope of this paper, as it requires analysis of data from tests on a large number of clays.

\section{The Effect of Wall Friction in the Bromhead Ring Shear Device}

As the use of the Bromhead ring shear device became more widespread, a number of researchers discovered that measured residual strengths were often dependent on details of the test procedure used (Anderson and Hammoud 1988; Stark and Vettel 1992; Stark and Eid 1993). Of particular concern was the fact that multistage Bromhead ring shear tests did not agree well with single-stage Bromhead ring shear tests (Anderson and Hammoud 1988; Stark and Vettel 1992). This finding was not consistent with the residual shearing behavior observed in the NGI-type ring shear device by Bishop et al. (1971). This discrepancy was attributed to wall friction that is developed as the top platen intrudes into the specimen container during shear (Stark and Vettel 1992). The link between soil extrusion, top platen intrusion, and development of wall friction is illustrated in Fig. 5. Stark and Vettel (1992) compared residual strengths measured using the Bromhead ring shear apparatus with those back calculated from field case histories, and concluded that the measured strengths are only accurate if the testing procedure that is used limits top platen intrusion to less than $0.75 \mathrm{~mm}$. Tiwari et al. (2005) found good agreement with residual shear strengths measured with a NGI-type ring shear apparatus and values back calculated from case histories of failures.

To address the issue of intrusion-induced wall friction, Stark and Vettel (1992) recommend that the "flush" test procedure should be used for Bromhead ring shear test-

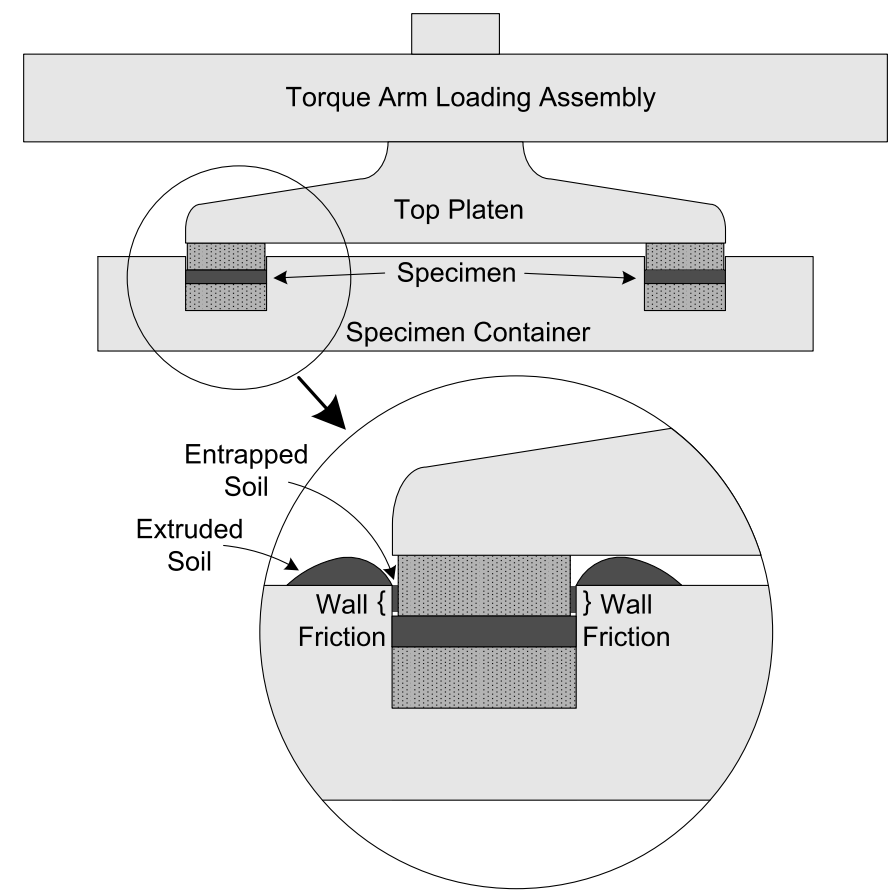

Fig. 5: Intrusion-induced wall friction in the Bromhead ring shear device.

ing. In the flush test procedure, after consolidation of the specimen has been completed, additional remolded soil is added to the specimen container, raising the top of the specimen, and the specimen is consolidated again, to provide a specimen of the maximum possible thickness, thus reducing intrusion of the top platen into the specimen container. As a further measure to reduce intrusion of the top platen, specimens are not presheared and only one test is performed on each specimen (single-stage test).

As noted by Stark and Vettel (1992), the "flush" testing procedure is more time consuming, and consequently, it is not desirable for widespread use. To address this issue, Stark and Eid (1993) proposed a new specimen container for the Bromhead ring shear apparatus that allows multistage testing of specimens without excessive top platen intrusion. Using this specimen container, remolded samples are preconsolidated to a high pressure, and then precut prior to shearing, which decreases the amount of displacement necessary to reach the residual condition. This reduces the amount of top platen intrusion for a given shearing stage, which makes it possible to run multistage tests without exceeding a top platen intrusion of $0.75 \mathrm{~mm}$. Test results show that this modified specimen container allows 
for a much more rapid determination of the residual shear strength than the "flush" test procedure, and gives results that agree well with results of back analyses of failures in the field. To the authors' knowledge, Stark and Eid's modified specimen container is not widely used with the Bromhead ring shear device. The reason for this is not clear, but it is possibly caused by the fact that some skill and experience are required to precut and test ring shear specimens using their test procedure, or because their proposed device modifications require construction of a completely new specimen container.

\section{Effect of Test Procedure on the Drained Residual Shear Strength}

In order to explore the sensitivity of the measured residual strengths to the test procedure that was used, a series of drained ring shear tests were conducted on Rancho Solano Fat Clay using a test procedure that was designed to reduce the effects of friction in the Bromhead ring shear device. Of specific concern was the effect of wall friction between the top platen and the walls of the specimen container, which can lead to residual strength values that are too high (Stark and Vettel 1992). As may be inferred from the sketch shown in Fig. 5, the magnitude of wall friction that is developed during shear is directly linked to the intrusion of the top platen into the specimen container.

The three primary causes of top platen intrusion in the Bromhead ring shear device are settlement due to consolidation, settlement due to soil extrusion during preshearing, and settlement due to soil extrusion during shearing. Although it is not possible to eliminate these sources of top platen intrusion completely, a number of modifications to the test procedure can be made to reduce the overall top platen intrusion during the tests. The modifications made to the test procedure are as follows:

- Test specimens were prepared at a lower water content. This reduced the amount of specimen consolidation. Lower water contents were achieved by preconsolidating remolded test specimens in a batch consolidometer to a normal stress of $345 \mathrm{kPa}$ prior to placement in the Bromhead ring shear specimen container.

- The specimens were not presheared. Although some soil extrusion and top platen intrusion occurred as the slickensided failure surface was created during slow shear, its magnitude was significantly less than that observed during more rapid preshearing.

- Each test was performed in a single stage. By testing a new specimen at each normal stress, it was possible to avoid the effect of accumulated soil extrusion and top platen intrusion that occurs at the second and third normal stresses in multistage tests.

Twenty-six "single-stage" ring shear tests were performed on Rancho Solano Fat Clay using these modifications to the test procedure. All specimens were sheared at a displacement rate of $0.018 \mathrm{~mm} / \mathrm{min}$. Specimens were tested at five normal stresses: 52, 100, 200, 345, and 590 $\mathrm{kPa}$. Typical test results from three "single-stage" ring shear tests are shown in Fig.6. For these tests, a small peak in stress was observed, followed by a gradual decrease in shear resistance to the residual strength, as the clay particles along the shearing plane were oriented in the direction of shear. This behavior was different than what was observed in the tests where preshearing was performed. Vertical displacement measurements were more variable than those measured in the presheared tests, with less correlation between the applied normal stress and the measured vertical displacement during shear. Larger vertical displacements were observed than those measured in the first series of tests, because soil extrusion is more pronounced in the Bromhead ring shear device during initial particle orientation along the shear plane.

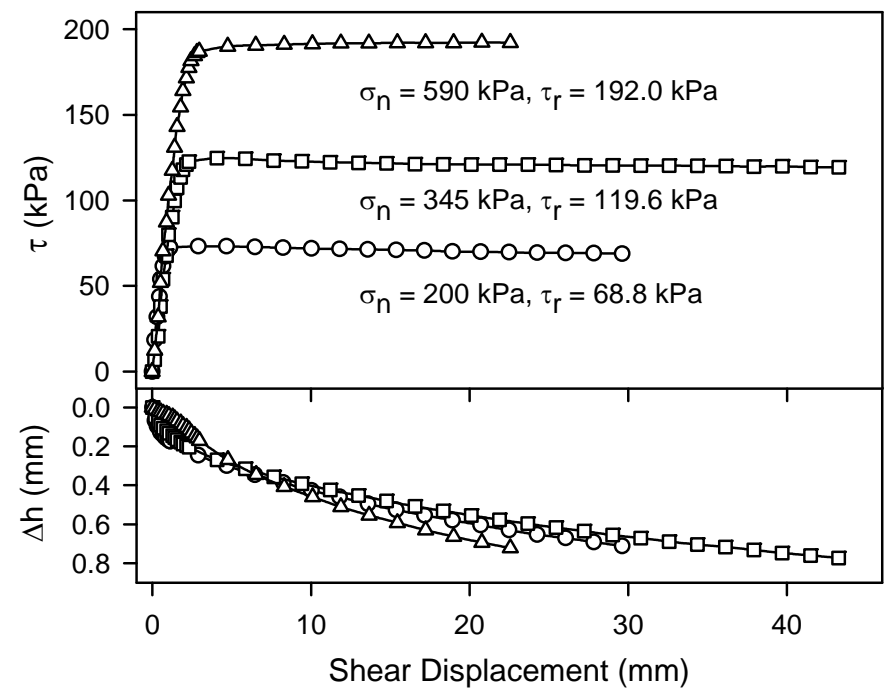

Fig. 6: Typical test results from three "single-stage" ring shear tests.

The results of statistical analyses performed on the measured residual shear strengths for the "single-stage" ring shear tests are given in Table 3. A plot of average residual shear stress versus normal stress for the "single-stage" ring shear tests and the "presheared multistage" ring shear tests is given in Fig. 7. The residual strength failure envelopes for these tests are also shown in Fig. 7. These envelopes were created by drawing smooth lines from the origin through the average residual shear stress values.

The data presented in Fig. 7 show the effect that wall friction has on residual strengths measured in the Bromhead ring shear device. These results suggest that the "single-stage" test approach reduces wall friction effects. However, even if the revised test procedures are used, wall friction in the Bromhead ring shear device will continue to affect measurements of the residual strength, because the procedures do not limit intrusion of the top platen into the specimen container to less than $0.75 \mathrm{~mm}$ (Stark and Vettel 1992). 
Table 3: Residual Shear Stresses Measured in "Single-Stage" Ring Shear Tests

\begin{tabular}{lccccc}
\hline $\begin{array}{l}\text { Normal } \\
\text { Stress } \\
(\mathrm{kPa})\end{array}$ & $\begin{array}{c}\text { Number } \\
\text { of Tests } \\
\text { Performed }\end{array}$ & $\begin{array}{c}\text { Average } \\
\text { Residual } \\
\text { Shear Stress } \\
(\mathrm{kPa})\end{array}$ & $\begin{array}{c}\text { Standard Deviation of } \\
\text { Measured Residual } \\
\text { Shear Stress } \\
(\mathrm{kPa})\end{array}$ & $\begin{array}{c}\text { Minimum } \\
\text { Measured Residual } \\
\text { Shear Stress } \\
(\mathrm{kPa})\end{array}$ & $\begin{array}{c}\text { Maximum } \\
\text { Measured Residual } \\
\text { Shear Stress } \\
(\mathrm{kPa})\end{array}$ \\
\hline 52 & 7 & 18.5 & 1.0 & 17.4 & 19.7 \\
100 & 4 & 35.7 & 0.8 & 34.8 & 36.5 \\
200 & 4 & 68.1 & 1.5 & 66.1 & 111.2 \\
345 & 6 & 114.1 & 3.3 & 183.1 & 194.9 \\
590 & 5 & 188.1 & 5.2 & & 19.6 \\
\hline
\end{tabular}

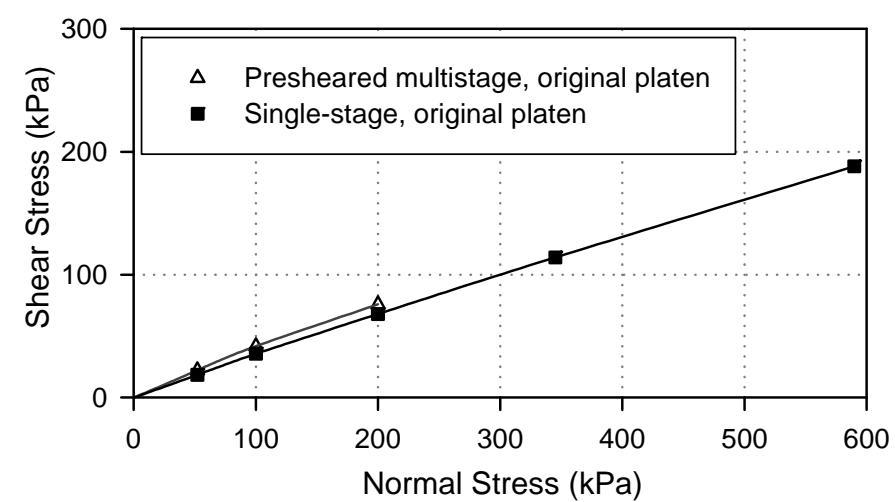

Fig. 7: Residual shear stresses measured in "single-stage" ring shear tests.

\section{Effect of Device Modifications on the Drained Residual Shear Strength}

In order to further increase the reliability of the residual strength measurements, a series of drained ring shear tests was conducted on Rancho Solano Fat Clay using a modified Bromhead ring shear device designed to reduce the effects of wall friction.

Wall friction in the Bromhead ring shear device is developed because the top platen intrudes into the specimen container, and soil is entrapped between the top platen and the side walls of the specimen container. By modifying the shape of the top platen, it is possible to reduce the pressures between the specimen container and the extruded soil to small values, thereby reducing wall friction to an insignificant level. The top platen was modified by cutting the inside and outside edges of the porous bronze loading platen back to a $45^{\circ}$ bevel, as shown in Figs. 8 and 9. As a result of this modification, significant wall friction cannot develop even if a large amount of top platen intrusion occurs during a test.

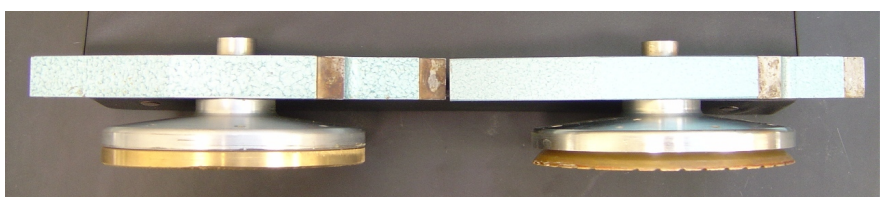

Fig. 8: Side view that shows the difference between the original porous bronze platen (on the left) and the modified porous bronze platen (on the right).

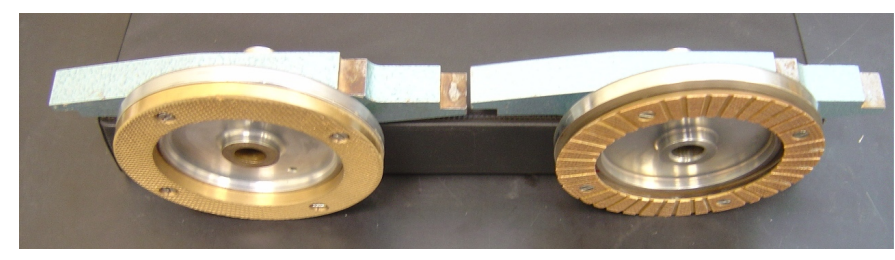

Fig. 9: Angle view that shows the difference between the original porous bronze platen (on the left) and the modified porous bronze platen (on the right).

Twenty-six "single-stage, modified platen" ring shear tests were performed on Rancho Solano Fat Clay using the "single-stage" test procedure in combination with the modification to the top platen described above. All specimens were sheared at a displacement rate of $0.018 \mathrm{~mm} / \mathrm{min}$. Specimens were tested at five normal stresses: 52, 100, 200,345 , and $590 \mathrm{kPa}$. Typical test results from three "single-stage, modified platen" ring shear tests are shown in Fig. 10.

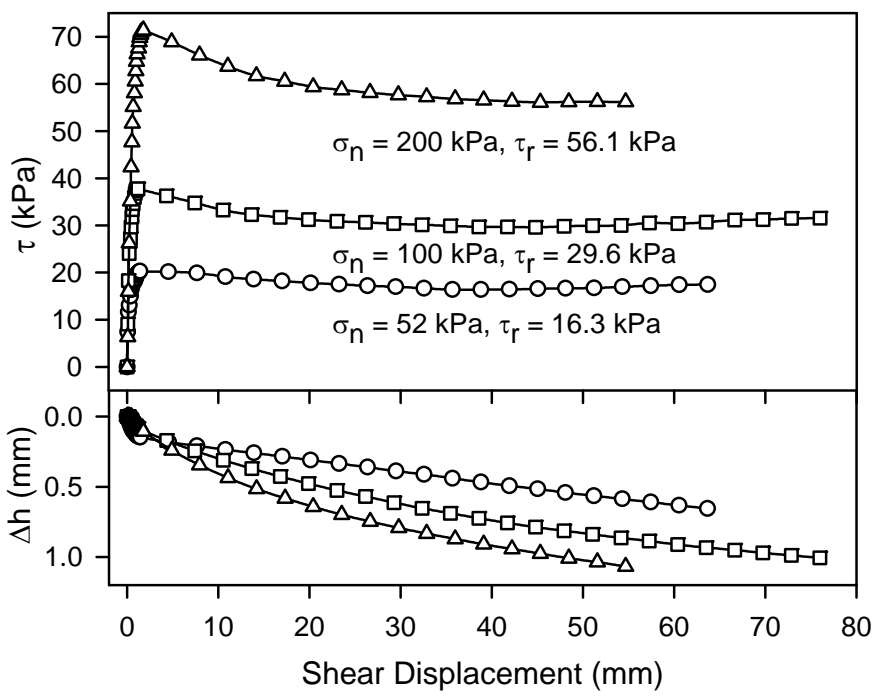

Fig. 10: Typical test results from three "single-stage, modified platen" ring shear tests.

For these tests, a defined peak in measured shear resistance was observed, followed by a gradual decrease in shear resistance to the residual strength. Vertical displacements during shear tended to increase with increasing normal stress, as soil extrusion around the edge of the beveled top platen was more pronounced at larger normal 
stresses. Larger vertical displacements were observed than those measured in the "single-stage, original platen" ring shear tests, because more soil extrusion occurred around the edges of the modified platen than around the edges of the original square-edged platen.

The results of statistical analyses performed on the measured residual shear strengths for the "single-stage, modified platen" ring shear tests are given in Table 4. A plot of average residual shear stress versus normal stress and residual strength envelopes for the "single-stage, modified platen" ring shear tests, the "single-stage, original platen" ring shear tests, and the "presheared multistage" ring shear tests is given in Fig. 11.

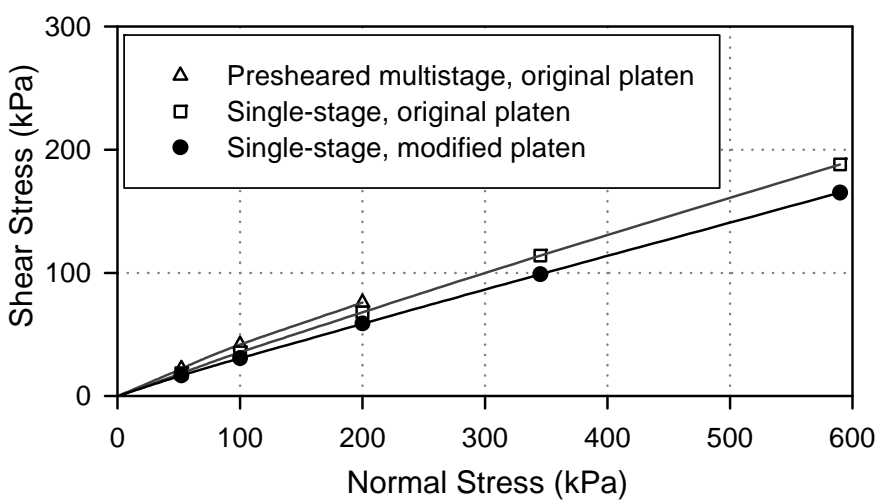

Fig. 11: Residual shear stresses measured in "single-stage, modified platen" ring shear tests.

Results from the Bromhead ring shear tests can also be interpreted using the secant phi approach discussed by Skempton (1985) and Stark and Eid (1994). This approach assumes that there is no residual cohesion, which leads to the following formula for calculation of the secant residual friction angle:

$$
\phi_{r}^{\prime}=\tan ^{-1}\left(\frac{\tau_{r}}{\sigma_{N}}\right)
$$

Statistical analysis results of the measured secant residual friction angles for the "presheared multistage," the "single-stage, original platen," and the "single-stage, modified platen" ring shear tests are given in Tables 5-7, respectively. A plot of average secant residual friction angle versus normal stress for the "presheared multistage," the "single-stage, original platen," and the "single-stage, modified platen" ring shear tests is given in Fig. 12. The bands above and below each friction angle value in Fig. 12 are the maximum and minimum secant residual friction angles measured at that normal stress.

The data presented in Figs. 11 and 12 show that the "single-stage, modified platen" ring shear tests successfully minimize the effect of wall friction in the Bromhead ring shear device, producing significantly lower values of drained residual strength than the "single-stage, original platen" tests. To confirm that the effect of wall friction was eliminated by modification of the top platen, a series of tests was conducted with the modified platen using

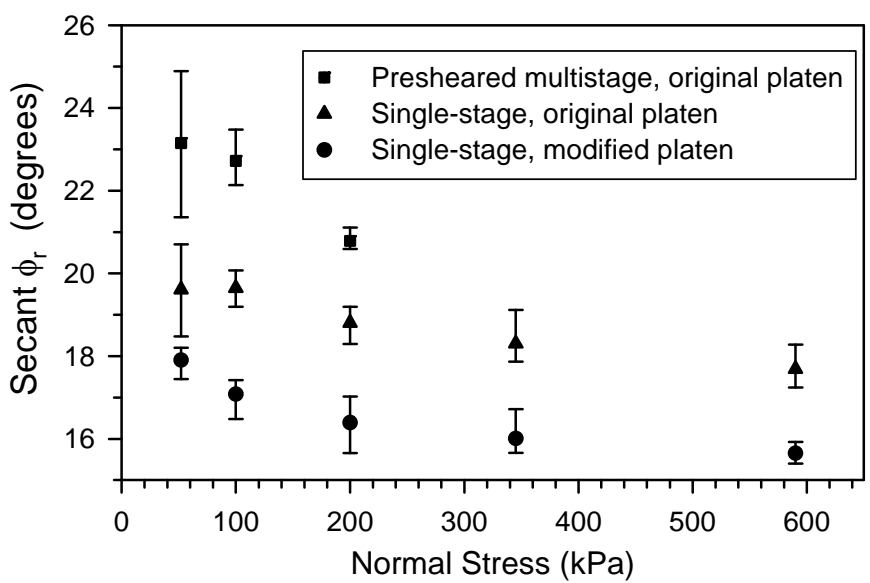

Fig. 12: Secant residual friction angles measured in "presheared multistage," "single-stage, original platen," and "singlestage, modified platen" ring shear tests.

the "single-stage" test procedure and a "presheared, multistage" test procedure that allowed significant intrusion of the top platen into the specimen container. A comparison of the measured shear stresses is shown in Fig. 13. For tests conducted with the modified platen, the presheared multistage test procedure gave residual strengths that were the same or slightly lower than tests conducted using the single-stage test procedure. These data show that the modified platen gives the same test results independent of the test procedure that is used (single stage or multi-stage), and that wall friction was successfully eliminated by modification of the top platen.

As shown in Fig. 13, when using the modified platen, it is often necessary to shear multistage specimens to large displacements to achieve a residual shear stress condition. This effect was regularly observed in multistage tests conducted with the modified platen. Additionally, the shape of the resulting stress-displacement curve often makes it difficult to select the appropriate residual strength.

\section{Conclusions}

Drained Bromhead ring shear tests were performed on Rancho Solano Fat Clay, following the procedure outlined in ASTM D 6467-99. Average measured secant residual friction angles for these "presheared multistage" tests ranged from $20.8^{\circ}$ to $23.2^{\circ}$. This range of values is due to variation of secant friction angles with normal stress.

Drained Bromhead ring shear tests were also conducted using the "single-stage" test procedure with the original square-edged platen, to compare the results of single-stage and multi-stage tests. Average measured secant residual friction angles ranged from $17.7^{\circ}$ to $19.6^{\circ}$ in the singlestage tests. These values were 10 to $15 \%$ lower than those measured following the "presheared multistage" test procedure with the original platen. This difference illustrates the link between top platen intrusion, developed wall friction, and measured shear resistance in the Bromhead ring shear device.

To further reduce the effect of wall friction in the Bromhead ring shear device, the top platen was modified by ma- 
Table 4: Residual Shear Stresses Measured in "Single-Stage, Modified Platen" Ring Shear Tests

\begin{tabular}{lccccc}
\hline $\begin{array}{l}\text { Normal } \\
\text { Stress } \\
(\mathrm{kPa})\end{array}$ & $\begin{array}{c}\text { Number } \\
\text { of Tests } \\
\text { Performed }\end{array}$ & $\begin{array}{c}\text { Average } \\
\text { Residual } \\
\text { Shear Stress } \\
(\mathrm{kPa})\end{array}$ & $\begin{array}{c}\text { Standard Deviation of } \\
\text { Measured Residual } \\
\text { Shear Stress } \\
(\mathrm{kPa})\end{array}$ & $\begin{array}{c}\text { Minimum } \\
\text { Measured Residual } \\
\text { Shear Stress } \\
(\mathrm{kPa})\end{array}$ & $\begin{array}{c}\text { Maximum } \\
\text { Measured Residual } \\
\text { Shear Stress } \\
(\mathrm{kPa})\end{array}$ \\
\hline 52 & 5 & 16.8 & 0.3 & 16.3 & 17.1 \\
100 & 4 & 30.7 & 0.8 & 29.6 & 31.4 \\
200 & 5 & 58.8 & 2.0 & 56.1 & 61.2 \\
345 & 6 & 99.0 & 2.4 & 96.7 & 103.6 \\
590 & 6 & 165.3 & 2.1 & 162.5 & 168.4 \\
\hline
\end{tabular}

Table 5: Values of Secant Residual Friction Angle Measured in "Presheared Multistage" Ring Shear Tests Using the Original Platen

\begin{tabular}{|c|c|c|c|c|c|}
\hline $\begin{array}{l}\text { Normal } \\
\text { Stress } \\
(\mathrm{kPa})\end{array}$ & $\begin{array}{c}\text { Number } \\
\text { of Tests } \\
\text { Performed }\end{array}$ & $\begin{array}{l}\text { Average Secant } \\
\text { Residual } \\
\text { Friction Angle } \\
\text { (degrees) }\end{array}$ & $\begin{array}{c}\text { Standard Deviation } \\
\text { of Measured } \\
\text { Secant Residual } \\
\text { Friction Angle } \\
\text { (degrees) }\end{array}$ & $\begin{array}{c}\text { Minimum } \\
\text { Measured } \\
\text { Secant Residual } \\
\text { Friction Angle } \\
\text { (degrees) }\end{array}$ & $\begin{array}{c}\text { Maximum } \\
\text { Measured } \\
\text { Secant Residual } \\
\text { Friction Angle } \\
\text { (degrees) }\end{array}$ \\
\hline 52 & 4 & 23.2 & 1.5 & 21.4 & 24.9 \\
\hline 100 & 4 & 22.7 & 0.6 & 22.1 & 23.5 \\
\hline 200 & 4 & 20.8 & 0.2 & 20.6 & 21.1 \\
\hline
\end{tabular}

chining the inside and outside edges of the porous bronze loading platen back to a $45^{\circ}$ bevel. "Single-stage, modified platen" tests gave average measured secant residual friction angles that ranged from $15.7^{\circ}$ to $17.9^{\circ}$. These strengths were 21 to $23 \%$ lower than those measured following the "presheared multistage" test procedure with the original platen. This difference shows the significant effect that wall friction has in the Bromhead ring shear device. Both single-stage and multi-stage "modified platen" tests gave the same residual strengths, showing that the modified platen eliminates the effect of wall friction associated with top platen intrusion.

To minimize the effect of wall friction in the Bromhead ring shear device, it is recommended that the top platen be modified as explained here. To reduce testing time, specimens can be prepared at a water content less than the liquid limit. "Presheared multistage" testing is not recommended with the modified platen, as it is often necessary to shear specimens to large displacements to achieve a constant shear stress, leading to increased test duration.

\section{Acknowledgments}

Funding for this research was provided by the National Science Foundation under Award Nos. CMS-0321789 and CMS-0324499 and by Virginia Tech, through the Instructorship Position. The authors would like to acknowledge the suggestions and assistance of Binod Tiwari, Derek Martowska, and Michael Wanger.

\section{References}

Anderson, W.F. and Hammoud, F., 1988, "Effect of Testing Procedure in Ring Shear Tests," Geotech. Test. J., ASTM, Vol. 11, No. 3, pp. 204-207.

ASTM Standard D 6467-99: Standard Test Method for Tor- sional Ring Shear Test to Determine Drained Residual Shear Strength of Cohesive Soils, Annual Book of Standards, Vol. 4, ASTM International, West Conshohocken, PA, 1999.

Bishop, A. W., Green, G. E., Garga, V.K., Andresen, A., and Brown, J.D., 1971, "A New Ring Shear Apparatus and Its Application to the Measurement of Residual Strength," Geotechnique, Vol. 21, No. 4, pp. 273-328.

Bromhead, E. N., 1979, "A Simple Ring Shear Apparatus," Ground Eng., Vol. 12, No. 5, pp. 40-44.

Duncan, J. M. and Wright, S. G., 2005, Soil Strength and Slope Stability, John Wiley \& Sons, Hoboken, NJ.

Lupini, J. F., Skinner, A.E., and Vaughan, P. R., 1981, "The Drained Residual Strength of Cohesive Soils," Geotechnique, Vol. 31, No. 2, pp. 181-213.

Meehan, C. L., 2006, "An Experimental Study of the Dynamic Behavior of Slickensided Slip Surfaces," Ph.D.thesis, Virginia Tech.

Skempton, A. W., 1964, "Long-Term Stability of Clay Slopes," Geotechnique, Vol. 14, No. 2, pp. 75-102.

Skempton, A. W., 1985, "Residual Strength of Clays in Landslides, Folded Strata, and the Laboratory," Geotechnique, Vol. 35, No. 1, pp. 3-18.

Stark, T.D. and Eid, H.T., 1993, "Modified Bromhead Ring Shear Apparatus," Geotech. Test. J., ASTM, Vol. 16, No.1, pp. 100-107.

Stark, T. D. and Eid, H. T., 1994, "Drained Residual Strength of Cohesive Soils," J. Geotech. Engrg., ASCE, Vol. 120, No. 5, pp. 856-871.

Stark, T. D. and Vettel, J. J., 1992, "Bromhead Ring Shear Test Procedure," Geotech. Test. J., ASTM, Vol. 15, No. 1, pp. 2432.

Tiwari, B., Brandon, T.L., Marui, H., and Tuladhar, G. R., 2005, "Comparison of Residual Shear Strengths from Back Analysis and Ring Shear Tests on Undisturbed and Remolded Specimens," J. Geotech. Geoenviron. Eng., ASCE, Vol. 131, No. 9, pp. 1071-1079.

Tiwari, B. and Marui, H., 2005, "A New Method for the Correlation of Residual Shear Strength of the Soil with Miner- 
alogical Composition," J. Geotech. Geoenviron. Eng., ASCE, Vol. 131, No. 9, pp. 1139-1150.

USACE, 1986, Laboratory Soils Testing - Engineer Manual
1110-2-1906, United States Army Corps of Engineers, Washington, DC. 
Table 6: Values of Secant Residual Friction Angle Measured in "Single-Stage" Ring Shear Tests Using the Original Platen

\begin{tabular}{lccccc}
\hline Normal & $\begin{array}{c}\text { Number } \\
\text { Af Tests } \\
(\mathrm{kPa})\end{array}$ & $\begin{array}{c}\text { Average Secant } \\
\text { Residual } \\
\text { Friction Angle } \\
\text { (degrees) }\end{array}$ & $\begin{array}{c}\text { Standard Deviation } \\
\text { of Measured } \\
\text { Secant Residual } \\
\text { Friction Angle } \\
\text { (degrees) }\end{array}$ & $\begin{array}{c}\text { Minimum } \\
\text { Measured } \\
\text { Secant Residual } \\
\text { Friction Angle } \\
\text { (degrees) }\end{array}$ & $\begin{array}{c}\text { Maximum } \\
\text { Measured } \\
\text { Secant Residual } \\
\text { Friction Angle } \\
\text { (degrees) }\end{array}$ \\
\hline 52 & 7 & 19.6 & 0.9 & 18.5 & 20.7 \\
100 & 4 & 19.6 & 0.5 & 19.2 & 20.1 \\
200 & 4 & 18.8 & 0.4 & 18.3 & 19.2 \\
345 & 6 & 18.3 & 0.5 & 17.9 & 19.1 \\
590 & 5 & 17.7 & 0.5 & & 17.2 \\
\hline
\end{tabular}

Table 7: Values of Secant Residual Friction Angle Measured in "Single-Stage, Modified Platen" Ring Shear Tests

\begin{tabular}{|c|c|c|c|c|c|}
\hline $\begin{array}{l}\text { Normal } \\
\text { Stress } \\
(\mathrm{kPa})\end{array}$ & $\begin{array}{c}\text { Number } \\
\text { of Tests } \\
\text { Performed }\end{array}$ & $\begin{array}{l}\text { Average Secant } \\
\text { Residual } \\
\text { Friction Angle } \\
\text { (degrees) }\end{array}$ & $\begin{array}{c}\text { Standard Deviation } \\
\text { of Measured } \\
\text { Secant Residual } \\
\text { Friction Angle } \\
\text { (degrees) }\end{array}$ & $\begin{array}{c}\text { Minimum } \\
\text { Measured } \\
\text { Secant Residual } \\
\text { Friction Angle } \\
\text { (degrees) }\end{array}$ & $\begin{array}{c}\text { Maximum } \\
\text { Measured } \\
\text { Secant Residual } \\
\text { Friction Angle } \\
\text { (degrees) }\end{array}$ \\
\hline 52 & 5 & 17.9 & 0.3 & 17.4 & 18.2 \\
\hline 100 & 4 & 17.1 & 0.4 & 16.5 & 17.4 \\
\hline 200 & 5 & 16.4 & 0.5 & 15.7 & 17.0 \\
\hline 345 & 6 & 16.0 & 0.4 & 15.7 & 16.7 \\
\hline 590 & 6 & 15.7 & 0.2 & 15.4 & 15.9 \\
\hline
\end{tabular}

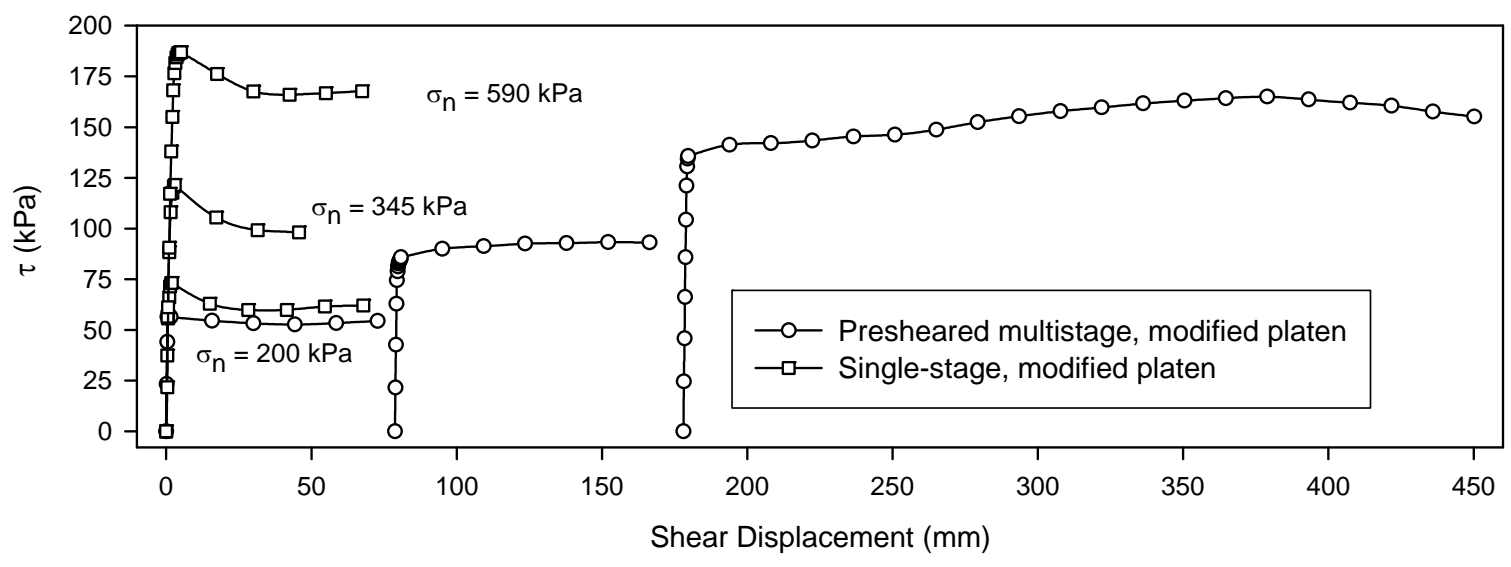

Fig. 13: A comparison between "modified platen" ring shear tests conducted using the "single-stage" test procedure and a "presheared multistage" test procedure. 